\title{
14 Industry Acceptance and Conclusion
}

\subsection{Introduction}

Historically, the adoption of new technology in established industries with mature infrastructures has been problematic. Existing systems, although they may not be as efficient or as effective as the newer technology, may be favoured because of: the long-term investment in the existing infrastructure; the challenge of integrating the new technology into the existing business; and a lack of understanding of the new technology and its potential by decision makers. Therefore, adoption of a new technology must be driven by the user and is often based on a clearly perceived need that can be better satisfied by the new technology rather than the existing infrastructure.

\subsection{Safety}

According to the Radiation Protection Standard for Maximum Exposure Levels (Australian Radiation Protection and Nuclear Safety Agency, 2002), the maximum time average operator exposure to electric fields at $2.45 \mathrm{GHz}$ is $137 \mathrm{~V} \mathrm{~m}^{-1}$ (RMS), while the exposure for the general public must be below $61.4 \mathrm{~V} \mathrm{~m}^{-1}$ (RMS).

Given the modern reliance on Global Positioning Systems (GPS) and precision farming, it is also important that microwave weed systems do not interfere with these systems. The global positioning system (GPS) makes use of medium altitude satellites to determine position, velocity and time at the receiver. GPS receivers can access the L1 (1.575 GHz), L2 (1.227 GHz), and L5 (1.176 GHz) bands (Falade, et al., 2012). Antennae on GPS receivers vary in their configuration, but micro-strip "patch" antennae are becoming more common because of their low profile, light weight, low cost, ruggedness, and conformability (Chang, et al., 1986).

Patch antennae provide variable bandwidths. For example, the stacked patch antenna, designed by Falade, et al. (2012), provides $10 \mathrm{~dB}$ of attenuation outside its operating bandwidths for GPS L1, L2, and L5 frequency bands, which are 1.160-1.182, 1.214-1.232, and 1.568-1.598 GHz, respectively. At frequencies outside these ranges, the coupling of microwave fields into the GPS receiver is very low. Exposure of GPS systems to microwave fields, at frequencies other than those used by the GPS system, should be limited to the same levels as exposure to the general public.

When the trailer prototype system was tested using a Tenmars TM-194 microwave leakage detector, the time average field strength at the location of the operator for the trailer system was $13.2 \mathrm{~V} \mathrm{~m}^{-1}$. The maximum measured field strength was $47.6 \mathrm{Vm}^{-1}$. This is well below the allowable exposure for both the operator and for the general public. 


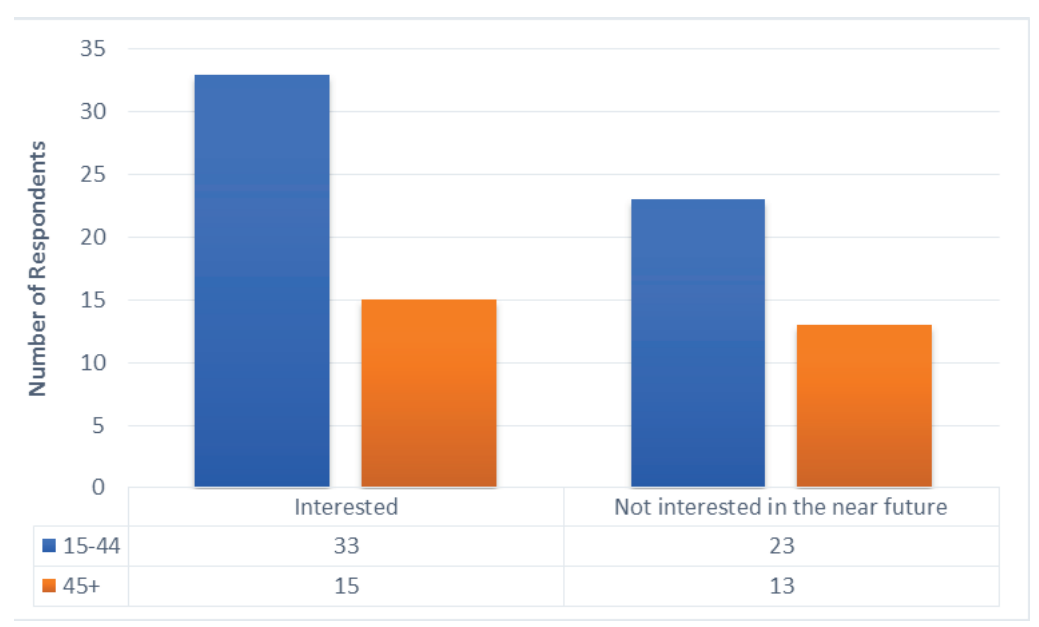

Figure 14.1: Response of rural community to their level of interest in trying microwave weed control technology, as a function of age.

The occasional burst of higher field strength is due to some channelling effects under the mental trailer and only extends a few centimetres above the ground.

The average field strength at the hitching point at the front of the trailer was 10.6 $\mathrm{V} \mathrm{m}^{-1}$. The maximum measured field strength was $32.5 \mathrm{~V} \mathrm{~m}^{-1}$. This also is well below the allowable exposure for both the operator and for the general public, and indicates that the exposure levels of a GPS system, which is further away from the microwave system than the hitching point, will have minimal exposure risk.

\subsection{Industry Acceptance}

A questionnaire was developed to capture data from farming communities around Australia. Although there was a small bias in the responses due to age of the respondents, there was some support for trying the microwave technology among the younger members of the rural community (Figure 14.1). Some comments suggested that microwave weed and soil treatment could find its first commercial applications in high value horticulture, as a substitute for soil fumigation, along road sides, or in urban applications, where concerns about chemical exposure is growing.

\subsection{Key Features of the Technology}

In summary, microwave technology can be used to kill already emerged weed plants, like a knock-down herbicide application, or it can be applied to the soil, like 
a soil fumigant. Experimental data, which has been gathered during this research programme, indicates that weed plant treatment requires a smaller amount of microwave energy than soil treatment; however, soil treatment appears to provide several additional benefits, which killing emerged plants does not. These include: direct control of the weed seed bank; control of several potentially pathogenic organisms (nematodes and fungi); enhanced crop growth; and some residual effect over two or more seasons.

\subsection{Summary}

Interest in the effects of high frequency electromagnetic waves on biological materials dates back to the late $19^{\text {th }}$ century (Ark and Parry, 1940), while interest in the effect of high frequency waves on plant material began in the 1920's (Ark and Parry, 1940). Many of the earlier experiments on plant material focused on the effect of radio frequencies (RF) on seeds (Ark and Parry, 1940). In many cases, short exposure resulted in increased germination and vigour of the emerging seedlings (Tran, 1979; Nelson and Stetson, 1985); however long exposure usually resulted in seed death (Ark and Parry 1940; Bebawi, et al., 2007; Brodie, et al., 2009).

Davis, et al. (1971; Davis, 1973) were among the first to study the lethal effect of microwave heating on seeds. They treated seeds, with and without any soil, in a microwave oven and showed that seed damage was mostly influenced by a combination of seed moisture content and the energy absorbed per seed. Other findings from the study by Davis, et al. (1971) suggested that both the specific mass and specific volume of the seeds were strongly related to a seed's susceptibility to damage by microwave fields (Davis, 1973). The association between the seed's volume and its susceptibility to microwave treatment may be linked to the "radar cross-section" (Wolf, et al., 1993) presented by seeds to propagating microwaves. Large radar cross-sections allow the seeds to intercept, and therefore absorb, more microwave energy.

Barker and Craker (1991) investigated the use of microwave heating in soils of varying moisture content (10-280 $\mathrm{g}$ water/kg of soil) to kill 'Ogle' Oat (Avena sativa) seeds and an undefined number of naturalised weed seeds present in their soil samples. Their results demonstrated that a seedlas susceptibility to microwave treatment is entirely temperature dependent. When the soil temperature rose to $75^{\circ} \mathrm{C}$ there was a sharp decline in both oat seed and naturalised weed seed germination. When the soil temperature rose above $80^{\circ} \mathrm{C}$, seed germination in all species was totally inhibited.

Several patents dealing with microwave treatment of weeds and their seeds have been registered (Haller, 2002; Clark and Kissell, 2003; Grigorov, 2003); however, none of these systems appear to have been commercially developed. This may be due to concerns about the energy requirements to manage weed seeds in the soil using microwave energy. In a theoretical argument based on the dielectric and 
density properties of seeds and soils, Nelson (Nelson, 1996) demonstrated that using microwaves to selectively heat seeds in the soil "cannot be expected". He concluded that seed susceptibility to damage from microwave treatment is a purely thermal effect, resulting from soil heating and thermal conduction into the seeds. This has been confirmed experimentally by Brodie, et al. (2007a).

Experience confirms that microwave energy can kill a range of weed seeds in the soil (Davis, et al., 1971; Davis 1973; Barker and Craker, 1991; Brodie, et al., 2009).

Pre-sowing microwave irradiation of soil minimises weed establishment (Davis, et al., 1971; Davis, 1973; Sartorato, et al., 2006; Brodie, et al., 2012; Brodie and Hollins, 2015). It can also destroy the weed reproductive plant parts and their seeds that are covered up by soil at a depth of several centimetres (Diprose, et al.1984; Brodie, et al., 2007b). Wayland et al. (1973) treated wheat and radish seeds in situ at $25 \mathrm{~mm}$ depth and moisture content of soil was $6.5 \%$. They found that microwave treatment was toxic to seeds with a threshold of $10 \mathrm{~J} \mathrm{~cm}^{-2}$ of energy density. Increasing power density was more effective at reducing the germination percentage of seeds than simply increasing energy density (exposure time at a fixed power level) for some species.

Davis et al. (1971) conducted an experiment to evaluate the effect of microwave treatment on the seedling survival percentage of twelve species. They described that the 48 hour germinated seedling showed no survival after a short exposure of microwave energy and concluded that susceptibility of young seedlings to microwave heating was highly correlated with moisture content and absorption of energy. Menges and Wayland (1974) compared post-emergence herbicides (methazoal, propachlor and perfluidone) with microwave at energy density of $45-720 \mathrm{~J} \mathrm{~cm}^{-2}$ for weed suppression in an onion crop. They reported that microwave $\left(360 \mathrm{~J} \mathrm{~cm}^{-2}\right)$ irradiation significantly inhibited weeds establishment. Additionally, minimum crop injury was noted in the case of microwave treatment (18\%) compared to herbicides application (85\%).

The current study has also demonstrated that microwave weed control can be applied to emerged weeds. The energy required to achieve plant mortality is usually less than that needed to treat soil; however, soil treatment offers several additional advantages over simple weed killing. These include: enhanced crop growth; better nitrogen use efficiency; control of some pathogenic organisms; and higher yields.

\subsection{General Conclusion}

Microwave energy can kill weed plants and their seeds in the soil. Chapter 8 explored the energy required to kill weed plants and Chapter 9 explored the energy needed to treat the soil using microwave energy. In Chapter 4, a summary table of energy expenditure for different types of weed management was developed. Microwave weed and soil treatment energy can now be slotted into the summary table. Weed plant treatment is comparable with herbicide treatment, while microwave soil treatment is comparable with soil fumigation. Both have a place in an integrated weed management strategy. 
Table 14.1: Updated summary of mean energy needs for various weed control strategies, on a per treatment basis.

\begin{tabular}{lll}
\hline Weed or Soil Treatment System & Main Application & $\begin{array}{l}\text { Mean energy Requirements } \\
\text { for complete coverage (G) ha') }\end{array}$ \\
\hline Steam soil treatment & Soil Fumigation & 1,190 \\
Laser & Weed Control & 233.5 \\
Steam - Weed control & Weed Control & 17.7 \\
Tillage & Weed Control & 17.5 \\
Hot water & Weed Control & 14.3 \\
Hand Hoeing & Weed Control & 10.8 \\
Microwave treatment - Soil treatment & Soil Fumigation & 10.0 \\
Ox drawn tillage & Weed Control & 5.2 \\
Flaming & Weed Control & 3.4 \\
IR & Weed Control & 3 \\
UV & Weed Control & 2.5 \\
Herbicide (Total energy, including & Weed Control & 1.4 \\
embodied energy for manufacture and & & \\
transport) & \\
Microwave treatment - weed plant & Weed Control \\
treatment & & \\
\hline
\end{tabular}

\subsection{References}

Ark, P. A. and Parry, W. (1940). Application of High-Frequency Electrostatic Fields in Agriculture. The Quarterly Review of Biology. 15(2), 172-191.

Australian Radiation Protection and Nuclear Safety Agency. (2002). RPS3 Radiation Protection Standard for Maximum Exposure Levels to Radiofrequency Fields $-3 \mathrm{kHz}$ to $300 \mathrm{GHz}$.

Barker, A. V. and Craker, L. E. (1991). Inhibition of weed seed germination by microwaves. Agronomy Journal. 83(2), 302-305.

Bebawi, F. F., Cooper, A. P., Brodie, G. I., Madigan, B. A., Vitelli, J. S., Worsley, K. J. and Davis, K. M. (2007). Effect of microwave radiation on seed mortality of rubber vine (Cryptostegia grandiflora R.Br.), parthenium (Parthenium hysterophorous L.) and bellyache bush (Jatropha gossypiifolia L.). Plant Protection Quarterly. 22(4), 136-142.

Brodie, G., Botta, C. and Woodworth, J. (2007a). Preliminary investigation into microwave soil pasteurization using wheat as a test species. Plant Protection Quarterly. 22(2), 72-75.

Brodie, G., Hamilton, S. and Woodworth, J. (2007b). An assessment of microwave soil pasteurization for killing seeds and weeds. Plant Protection Quarterly. 22(4), 143-149.

Brodie, G., Harris, G., Pasma, L., Travers, A., Leyson, D., Lancaster, C. and Woodworth, J. (2009). Microwave soil heating for controlling ryegrass seed germination. Transactions of the American Society of Agricultural and Biological Engineers. 52(1), 295-302.

Brodie, G. and Hollins, E. (2015). The Effect of Microwave Treatment on Ryegrass and Wild Radish Plants and Seeds. Global Journal of Agricultural Innovation, Research \& Development. 2(1), 16-24. 
Brodie, G., Ryan, C. and Lancaster, C. (2012). The effect of microwave radiation on Paddy Melon (Cucumis myriocarpus). International Journal of Agronomy. 2012, 1-10.

Clark, W. J. and Kissell, C. W. (2003). System and Method for In Situ Soil Sterilization, Insect Extermination and Weed Killing. Patent No. 20030215354 A1.

Davis, F. S., Wayland, J. R. and Merkle, M. G. (1971). Ultrahigh-Frequency Electromagnetic Fields for Weed Control: Phytotoxicity and Selectivity. Science. 173(3996), 535-537.

Davis, F. S., Wayland, J. R. and Merkle, M. G. (1973). Phytotoxicity of a UHF Electromagnetic Field. Nature. 241(5387), 291-292.

Diprose, M. F., Benson, F. A. and Willis, A. J. (1984). The Effect of Externally Applied Electrostatic Fields, Microwave Radiation and Electric Currents on Plants and Other Organisms, with Special Reference to Weed Control. Botanical Review. 50(2), 171-223.

Grigorov, G. R. (2003). Method and System for Exterminating Pests, Weeds and Pathogens. Patent No. 20030037482A1.

Haller, H. E. (2002). Microwave Energy Applicator. Patent No. 20020090268 A1.

Menges, R. M. and Wayland, J. R. (1974). UHF electromagnetic energy for weed control in vegetables. Weed Science. 22(6), 584-590.

Nelson, S. O. (1996). A review and assessment of microwave energy for soil treatment to control pests. Transactions of the ASAE. 39(1), 281-289.

Nelson, S. O. and Stetson, L. E. (1985). Germination responses of selected plant species to RF electrical seed treatment. Transactions of the ASAE. 28(6), 2051-2058.

Sartorato, I., Zanin, G., Baldoin, C. and De Zanche, C. (2006). Observations on the potential of microwaves for weed control. Weed Research. 46(1), 1-9.

Tran, V. N. (1979). Effects of Microwave Energy on the Strophiole, Seed Coat and Germination of Acacia Seeds. Australian Journal of Plant Physiology. 6(3), 277-287.

Wayland, J. R., Davis, F. S. and Merkle, M. G. (1973). Toxicity of an UHF Device to Plant Seeds in Soil. (3), 161.

Wolf, W. W., Vaughn, C. R., Harris, R. and Loper, G. M. (1993). Insect radar cross-section for aerial density measurement and target classification. Transactions of the American Society of Agricultural and Biological Engineers. 36(3), 949-954. 